\title{
A Review of Nusslet Number under Laminar Flow Condition in Heat Exchanger
}

\author{
K Ashok Reddy ${ }^{\mathrm{a}}$, M Bhagvanth Rao ${ }^{\mathrm{b}}$ and P Ram Reddy ${ }^{\mathrm{c}}$ \\ a Dept.of Mechanical Engg. ,Prof.Rama Reddy College of Engg \& Tech. Nandigamma(V), Pantacheru(M) Dist \\ Medak-503 200 A.P. \\ $b$ Dept of Chemical Engg CVSR College of Engineering Uppal Road, Greater Hyderabad A. P. \\ c. Dept.of Mechanical Engg., Malla Reddy College of Engg, Masimaaguda, Hyderabad A.P.
}

\begin{abstract}
We present the results of measured heat transfer coefficients for different sodium car boxy methyl cellulose concentrations at two different lengths of coil $L=2.82 \mathrm{~m}, L=2.362 \mathrm{~m}$ and with two different heat inputs $1.0 \mathrm{~kW}$ and $1.5 \mathrm{~kW}$. Test solutions of sodium carboxymethyl cellulose concentrations of $0.05 \%, 0.1 \%, 0.15 \%$ and $0.2 \%$ were used in our experimental runs. The rheological properties like flow behavior index, consistency index and viscosity data were measured experimentally using Rotating Cylinder Method for the test solutions used. Correlations are presented for Newtonian and non Newtonian fluids in laminar flow conditions. Individual heat transfer coefficients of the helical coil has been evaluated using modified Wilson Plot at different flow rates. A helical coil with diameter $D=156 \mathrm{~mm}$, constant pitch $=6 \mathrm{~mm}$ and having three turns was used in our study. A four flat blade paddle impeller was used to verify the mixed fluid, under unsteady heating of Newtonian and non-Newtonian fluids in an flat bottom agitated vessel without baffles. The curvature ratio $\delta=0.04102$ is maintained constant. A Kanthal Heating Element Equipment have been design and fabricated to optimize the heating of the fluids in an agitated vessel.
\end{abstract}

\section{Introduction}

Tube coils offer substantial amount of heat transfer area at a considerably low cost. Coils have lower wall resistance and show better performance in achieving the better heat transfer rates. Due to turn of helix angle, centrifugal force is generated inside the coil and hence the heat transfer rates with helical coil arrangement is better than the corresponding straight coil.

The tubes are coiled into helices in which inlet and outlet are conveniently located side by side. When such coils are used with impeller, they tend to increase the side wall heat transfer rates. For ordinary use, it is suggested that the straight tube equation such as Sieder-Tate [1] relation can be used, when the value of $\mathrm{h}$ so obtained is multiplied by $\left[1+3.5\left(\mathrm{~d} / \mathrm{d}_{\mathrm{c}}\right)\right]$ where $\mathrm{d}$ is the inside diameter of the tube and $\mathrm{d}_{\mathrm{c}}$ is the diameter of the coil helix.

As far as mechanical agitation is concerned, heat transfer through conducting surface improves with agitation as contact with the heat transfer area is improved. As far as the inside coefficient for the coil is concerned the increased turbulence due to circulatory path, the heat transfer coefficient will be greater than those calculated for straight tubes. Helical coils arrangements in a agitated vessel show significant experimental results for unsteady state of bulk temperature profiles leading to higher heat transfer rates compared to the jacketed agitated vessel.

The main objectives of this work are :

To design and fabricate the kanthal heating element embedded in knitted glass fabric type heating apparatus to evaluate heat transfer in immersion coil with different flow rates and two different coil length in the convective heat transfer mode.

To determine the viscosity by using rotating cylinder viscometer and to analyze the data so obtained with regression analysis.

To determine the overall heat transfer coefficient for outer diameter of the helical coil and evaluate the individual heat transfer coefficients by using the theoretical empirical equations found in the literature.

\subsection{Design of the Knathal Heating Element:}

\section{Materials \& Methods:}

Based on the published data [2,3,4], the design and fabrication of equipment used for this investigations has been carried out and details are given as under:

The heating element consists of $80 \%$ Nickel and 20\% Chromium which has been long regarded as finest alloy of its type for better performance resistance heating. It gives outstanding performance. Normally manufacturer test these alloys by Bash and Harwich life test. The wire is heated at fixed temperature for two 
minutes and allowed to cool for two minutes. The heating and cooling cycle is conformed to till the wire burns out. Nichrome 80/20 was selected for designing the heating element.

With 80/20 Ni Cr, the effects of repeated heating -cooling are far less compared to other alloys because the chromium rich oxide formed is more adherent than other oxides formed by iron containing alloys. After selection of suitable alloy, the diameter of wire is to be selected. On selection of diameter, to accommodate the length of the wire, they are made in spiral form at slow speed on suitable mandrel. The mandrel size should not exceed five times the wire diameter otherwise the element will not have mechanical strength to hold in the position. After making spiral, it is stretched to two half times length for uniform emitting of heat and to avoid heat losses.

The lead should have lower resistivity - at least three times the same wire is used to form a lead and twisted together to form connection. The wire emits its generated heat from its surface area and with higher surface area one can provide higher wattage .It is called surface loading. This factor determines life and temperature of the element, on the basis of the selection of insulation to be provided .The elevated temperature in the process vessel is either required to distill liquids or to produce chemical changes due to combination of temperature and chemical treatment. Here, we require to measure heat transfer through different liquids. As we need temperature requirement of $200 / 300^{\circ} \mathrm{C}$, we have selected lower surface loading i.e Watts $/ \mathrm{cm}^{2}$ such that the heating element works on high temperature $\left(550^{\circ} \mathrm{C}\right)$, hence fiber glass yarn has been selected as electrical insulating material. Fiber glass is not only good electrical insulation but also good conductor of heat i.e heat generated will be transformed through surface area of the heater. The fiber glass yarn can withstand peak temperature of $550^{\circ} \mathrm{C}$, normally limited to $450^{\circ} \mathrm{C}$ and suitable for liquid temperature of $350^{\circ} \mathrm{C}$. The fiber glass yarn is knitted as fabric, so that the fabric is flexible, resistant and can be made to adopt to small difference in size of the vessel, perfectly. The knitted fabric is made to the shape of vessel used in the experiment and the elements are attached to it such that it gets embedded and forms part of the fiber glass fabrication.

The vessel is made of stainless steel and by taking into account approximate heat required, selection was made to have $1.5 \mathrm{~kW}$ heater in three sections each of 500 Watts with selectable through individual toggle switches. This has been done purposely to select the heater as per quantity of material used in the experiment, to get better accuracy by avoiding high heating to prevent over shooting the temperature. This entire heating system is lagged with approximately $0.05 \mathrm{~m}$ thickness of insulation of glass wool to avoid heat loss to surface and utilize entire heat energy.

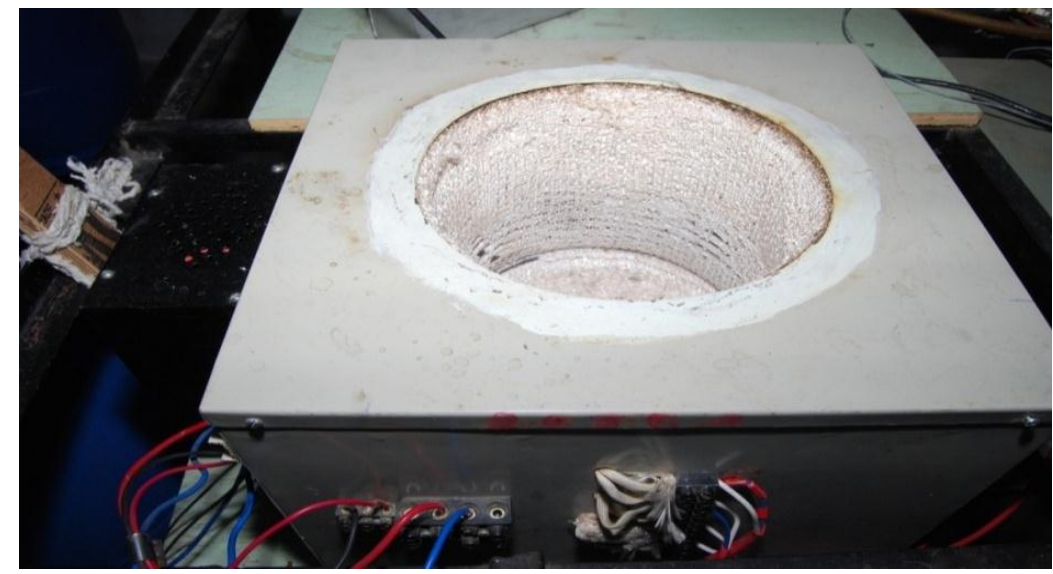

Fig.1 Kanthal Heating Element Apparatus

\section{2,2 Evaluation of Viscosity:}

The Rotating Cylinder Viscometer [5] has been used to evaluate the viscosity of $0.05 \% \mathrm{CMC}, 0.1 \% \mathrm{CMC}, 0.15 \% \mathrm{CMC}$ and $0.2 \% \mathrm{CMC}$ test solutions. It has RS-232 interface with data interoperation system and preset adjustment for shear rate in the range 1 to $600 \mathrm{rpm}$. For our study the Ostwald model regression method is taken into consideration and the model equation is taken as $\tau=\mu$. (y) ${ }^{\mathrm{n}}$ The ranges for different concentrations: Viscosity Range: 1000-1100 C.P. and Shear Rate Range: 1-200 s ${ }^{-1}$ Temperature difference for each reading $=5^{0} \mathrm{C}$.

It is evident from the Fig 2 , that the viscosity is constant for Newtonian fluids and it varies with temperature for non Newtonian fluids.

One can be inferred from the Fig 3 that consistency index decrease as the temperature of the test solution increase and obeys power law model for non Newtonian fluids. 


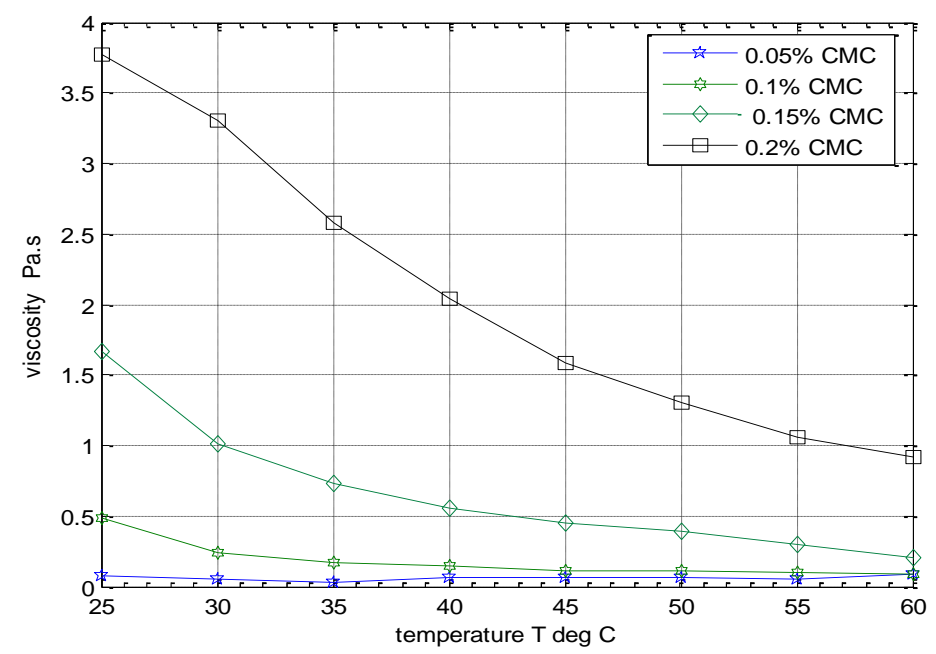

Fig 2 dependence of viscosity on temperature for $0.05 \%, 0.1 \%, 0.15 \%$ and $0.2 \%$ CMC test solutions.

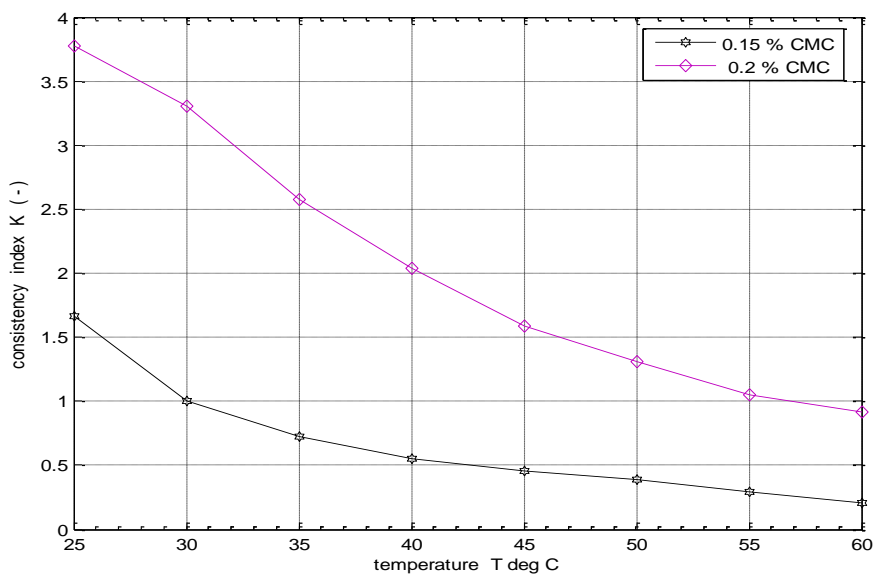

Fig 3 dependence of consistency index on temperature for $0.15 \%$ and $0.2 \% \mathrm{CMC}$ Conc.

\section{Results and Discussions:}

\subsection{Determination of Over all Heat Transfer Coefficients $\left(\overline{\mathbf{U}}_{\mathbf{o}}\right)$ :}

The overall heat transfer coefficient of the helical coil has been evaluated by using the heat balance equation[6]:

$\mathrm{Q}^{*} \rho^{*} \mathrm{C}_{\mathrm{p}} *\left(\mathrm{~T}_{\mathrm{o}}-\mathrm{T}_{\mathrm{i}}\right)=\mathrm{U}\left(\mathrm{A} *\left(\mathrm{~T}_{\mathrm{b}}-\left(\mathrm{T}_{\mathrm{o}}+\mathrm{T}_{\mathrm{i}}\right) / 2\right)\right.$

The properties of density $(\rho)$ and specific heat $\left(\mathrm{C}_{\mathrm{p}}\right)$ are taken into account at the average inlet temperature of $T_{i}$, where the maximum outlet temperature of the coil $T_{o}$ being in our experiments. relation[5]:

Time average overall heat transfer coefficient of the helical coil was evaluated by using following $\overline{\mathrm{U}}=\sum \mathrm{U} \mathrm{t}_{\mathrm{j}} \Delta \mathrm{t}_{\mathrm{j}} / \sum \mathrm{t}_{\mathrm{j}} \Delta \mathrm{t}_{\mathrm{j}}$

Time average overall heat transfer coefficients have been evaluated from the above two equations (12) for each test run using $\mathrm{C}$ Program and Matlab7.0 . In our present study, the thermal properties like density $(\rho)$,thermal conductivity $(\mathrm{k})$ and specific heat $(\mathrm{Cp})$ have been taken from the literature [7].

\subsection{Effect of Impeller Speed:}

Observations were made with impeller rotational speeds varying from 40-120 rpm for Newtonian fluids and 40-250 rpm for non-Newtonian fluids. Impeller speed variation was found to have a pronounced effect on the Nusselt number. Increased mechanical agitation caused vigorous mixing, with consequent reduction in the thickness of the liquid film and thus increased values of Nusselt numbers. The effect of mechanical agitation on the value of the overall heat transfer coefficient was not appreciable for Newtonian and non Newtonian fluids under laminar flow condition. ( Fig 4) 


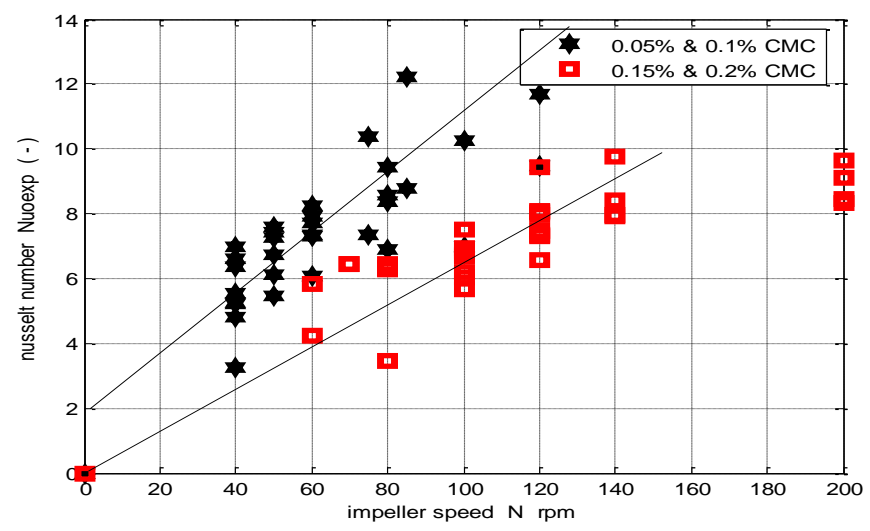

Fig 4 dependence of impeller speed on nusselt number for Newtonian and non Newtonian fluids

\subsection{Determination of Nusselt Number:}

\section{Newtonian Fluids}

Newtonian fluids with Re:20-250, curvature ratio $\lambda=0.0256$ and Pr:150-800 Viscosity index:1.2-4.4 Rotational Speed N:40-120rpm were found to be in good agreement with the parameters used in obtaining the following relation $\mathrm{Nu}_{0}=0.0366(\operatorname{Re})^{0.6127}(\operatorname{Pr})^{0.4478}(\mathrm{Viss})^{0.14}$

Varying the density $(\rho)$, impeller rotational speed(N) \& Viscosity of the test solution,the theoretical Nusselt Number $\left(\mathrm{Nu}_{\mathrm{o}}\right)$ for the helical coil of Newtonian fluids have been evaluated using equation (3).Thermal conductivity (k) and specific heat (Cp) of $0.05 \%$ and $0.1 \% \mathrm{CMC}$ test solutions were kept constant.

The Reynolds index was found to be 0.6127 , which is in good agreement with the most commonly reported value being 0.66[] .The Prandtl index was found to be 0.4478 .The index reported by different authors ranged between 0.25 and 0.50 , the most commonly reported value being 0.33 . The reason for deviation is possibly uncontrollable heat losses to the surroundings .

Fig 5 shows the comparison of experimental Nusselt Number for outer diameter of the helical coil with theoretical Nusselt Number for $0.05 \%$ and $0.1 \%$ CMC test solutions showing Newtonian behavior and being evaluated using equation (3). The correlation coefficient is found to be good agreement with test solutions as $\mathrm{R}^{2}$ $=0.804$

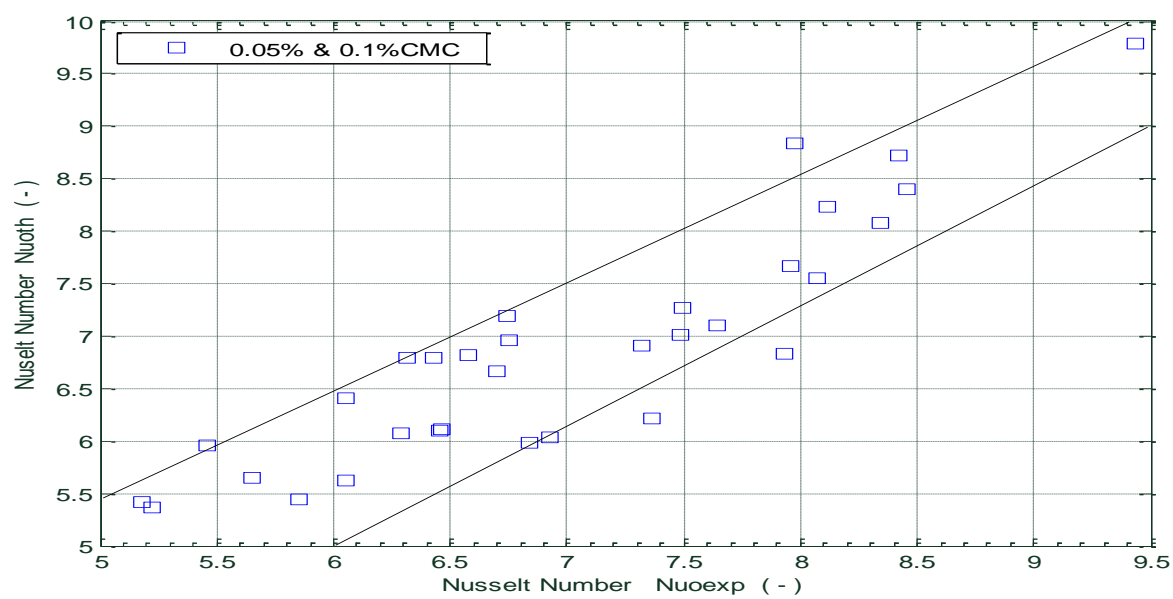

Fig 5 Comparison of $\mathrm{Nu}_{\text {oexp }}$ with $\mathrm{Nu}_{\text {oth }}$ for Newtonian Fluids

\section{Non-Newtonian Fluids:}

Dean Number :2.5-60, Rotational Speed N:60-200rpm

Theoretical Nusselt number $\left(h_{0}\right)$ for the helical coil of non-Newtonian fluids have been evaluated using the following equation

$\mathrm{Nu}_{\mathrm{o}}=\mathrm{C}(\mathrm{De})^{\mathrm{a}}$

Taking $\log$ on both sides for the above equation(4), we get

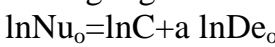


Using Regression Method, the constants $\mathrm{C}$ and a in the equation(5) have been evaluated and substituted in the equation(6)

$\mathrm{Nu}_{0}=1.7(\mathrm{De})^{0.0955}$

Varying density $(\rho)$, consistency index $(\mathrm{K})$ and impeller rotational speed(N), the $\mathrm{Nu}_{\mathrm{o}}$ have been evaluated using equations (4-6) with thermal conductivity (k), flow behavior index (n) and specific heat (Cp) of $0.15 \%$ and $0.2 \% \mathrm{CMC}$ test solutions were kept constant.

Re: 15-300,Pr: $1200-5200, \mathrm{~K}_{\mathrm{m}} / \mathrm{K}_{\mathrm{w}}=2.2-5.4$ Rotational Speed $\mathrm{N}=60-200 \mathrm{rpm}$

$\mathrm{Nu}_{\mathrm{o}} \operatorname{Pr}{ }^{0.4325}=8.16 \mathrm{Re}^{0.3694}\left(\mathrm{~K}_{\mathrm{m}} / \mathrm{K}_{\mathrm{w}}{ }^{0.14}\right.$

The Reynolds index was found to be 0.3694 , the most commonly reported value being 0.66[].The Prandtl index was found to be -0.4325 , the most commonly reported value being 0.33 . Our heat transfer coefficients and consequently the Nusselt Numbers are slightly higher than those found in the literature. This may be attributed to the fact that heat transfer area of the helical coil in our setup is located near the flat bottom of the agitated vessel.

It can be inferred from the Fig 6 that the trend line is parallel and increasing, when comparing the data for experimental Nusselt Number with theoretical Nusselt Number for non-Newtonian test solutions. The correlation coefficient is found to be good agreement with test solutions as $\mathrm{R}^{2}=0.875$ for the above equation (7).

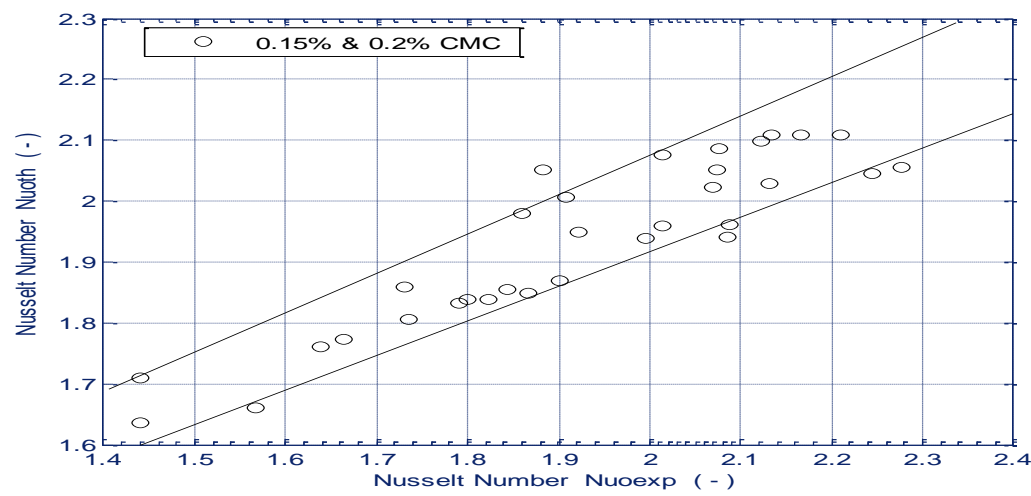

Fig 6 Comparison of $\mathrm{Nu}_{\text {oexp }}$ with $\mathrm{Nu}_{\text {oth }}$ for non-Newtonian Fluids

\section{Conclusion:}

1.The rheological property that is the consistency index (K) equation s have developed for nonNewtonian fluids. The equations are as $\mathbf{K}=\mathbf{5 7 5 7} * \mathbf{T}^{-\mathbf{2 . 5}}(0.15 \% \mathrm{CMC})$ and $\mathbf{K}=\mathbf{1 4 4 8} * \mathbf{T}^{\mathbf{- 1 . 7 8}}(0.2 \% \mathrm{CMC})$. The equations were evaluated using regression analysis. The consistency index $(\mathrm{K})$ decreases as the temperature of the test solution increases ( Fig 2 )

2.CMC test solutions $0.05 \%$ and $0.1 \%$ shows Newtonian behavior of linear equation $\mathrm{Nu}_{\text {oth }}=0.935\left(\mathrm{Nu}_{\text {oexp }}\right)+$ 0.327 .

3. Non-Newtonian test solutions $0.15 \%$ and $0.2 \%$ have shown good agreement with power law equation $\mathrm{Nu}_{\text {oth }}=1.347\left(\mathrm{Nu}_{\text {oexp }}\right)^{0.554}$.

\section{Acknowledgement:}

At the outset, I sincerely thank and extend my gratitude to the Management of Prof Rama Reddy College of Engineering \& Technology Nandigaon(V) Pantnacheru (M) Medak Dist. A. P. for allowing me to establish the experimental setup and use the college facilities for carrying out my experimental work.

\section{Referances}

[1]. $\quad$ E N Sieder \& G N Tate; Heat Transfer \& Pressure Drop of Liquids in Tube, Inds. Engineering Chemistry 28 (1936) p1429.

[2]. Kanthal; Handbook Wikipedia, Encyclopedia, Hallstahammer Sweden p106-115

[3]. Kanthal; Handbook Heating Alloys for Electric Household Appliances Design Factors p20-41

[4]. Kanthal; Handbook - Resistance Heating Alloys \& Systems for Industrial Furnaces p1-28

[5]. Hakes Information Hakes Mess-Technique; GmbH Co Diesis stir Germany VT500 Hakes Visio tester p1-10

[6]. Y P Settee \& N S Jaya Kumar; Heat Transfer Studies Using Half-Coil Jacket, Indian Chemical Engineer ( A ) 41 (1999) T27-

[7]. A M Mondal, J A Naser \& A K M A Quader; Laminar Heat Transfer to Time-Independent Non-Newtonian Fluids in Tubes Indian Chemical Engineer Section A 391997 T27-T34 